\title{
Avaliação do Impacto de Secas Severas no Nordeste Brasileiro na Geração de Energia Elétrica Através do Modelo Newave: Projeção das Energias \\ Afluentes e Armazenadas
}

\author{
Rafaella de Araújo Aires $\operatorname{Vilar}^{1}$ (D), Magaly de Fátima Correia ${ }^{1}$, Ranyére Silva Nóbrega ${ }^{2}$, \\ Maria Regina da Silva Aragão ${ }^{1}$, Leonardo Fagner Ponciano Barbieri ${ }^{1}$, \\ Mario Gameiro de Moura Filho ${ }^{3}$ \\ ${ }^{1}$ Programa de Pós-Graduação em Meteorologia, Universidade Federal de Campina Grande, \\ Campina Grande, PB, Brasil. \\ ${ }^{2}$ Programa de Pós-Graduação em Geografia, Departamento de Ciências Geográficas, \\ Universidade Federal de Pernambuco, Recife, PE, Brasil. \\ ${ }^{3}$ Kroma Energia Ltda, Recife, PE, Brasil.
}

Recebido em: 29 de Outubro de 2019 - Aceito em: 7 de Janeiro de 2020

\begin{abstract}
Resumo
Em situações críticas decorrentes de níveis baixos dos reservatórios das hidrelétricas, o controle do setor elétrico brasileiro é feito com base em planejamento hidrotérmico que dependem das vazões afluentes futuras às Usinas Hidrelétricas (UHEs). As incertezas hidrológicas são consideradas por meio de cenários sintéticos de sequências de energias naturais afluentes às sub-regiões. Dois modelos computacionais são usados para otimizar o sistema: o NEWAVE (médio e longo prazo) e o DECOMP (curto prazo). O NEWAVE é um modelo de planejamento energético aplicado ao Sistema Interligado Nacional (SIN) que utiliza a Programação Dinâmica Dual Estocástica (PDDE) para determinar a política operativa que minimiza o custo marginal de operação em um horizonte de até 5 anos. O desenvolvimento deste trabalho tem como objetivo avaliar o desempenho do NEWAVE através da funcionalidade NWLISTOP na projeção das Energia Natural Afluente (ENA) e da Energia Armazenada (EAR) no Subsistema Nordeste (NE) para os anos de 2012 a 2016. Verificou-se que o modelo tende a superestimar os valores das ENA e EAR. Os resultados indicam a necessidade do uso de técnicas que permitam otimizar o planejamento de operação a longo prazo, principalmente em episódios de seca extrema.
\end{abstract}

Palavras-chave: UHE de Sobradinho, energia afluente, energia armazenada, modelo NEWAVE.

\section{Impact Evaluation of Dried Dryes in the Northeast Brazil on Electric Power Generation Through the Newave Model: Projection of Afluent and Stored Energies}

\begin{abstract}
In critical situations due to low levels in the hydroelectric reservoirs, the control of the Brazilian electric sector is made based on hydrothermal planning which depends on the future affluent flows to the Hydroelectric Power Plants (HPPs). The hydrologic uncertainties are considered by means of synthetic scenarios of sequences of affluent natural energies to the sub-regions. Two computational models are used to optimize the system: the NEWAVE (medium and long-range) and the DECOMP (short-range). The NEWAVE is a model of energetic planning applied to the National Interconnected System (NIS) which uses the Dual Dynamic Stochastic Programming (UDSP) to determine the operational policy that minimizes the marginal cost of operation of the energy sector in a horizon of up to 5 years. The objective in developing
\end{abstract}

Autor de correspondência: Rafaella de Araújo Aires Vilar, rafaella.aavilar@yahoo.com. 
this work is to evaluate the performance of the NEWAVE model through the NWLISTOP functionality in the projection of the affluent natural energy (ANE) and the stored energy (STE) in the Northeast Subsystem for the years from 2012 to 2016. It was verified that the model tends to overestimate the ANE and STE values. The results indicate the need to use techniques that allow to optimize the long-range operational planning, mainly in situations of extreme drought episodes.

Keywords: Sobradinho Hydroelectric Power Plant, Affluent Energy, Stored Energy, NEWAVE model.

\section{Introdução}

O Operador Nacional do Sistema Elétrico (ONS) é o órgão responsável pelas atividades de coordenação e controle da operação de geração e transmissão, no âmbito do Sistema Nacional Interligado (SIN). Por sua vez o SIN é composto por quatro subsistemas geradores/consumidores interligados, o Sudeste/Centro-Oeste, o Sul, o Nordeste e o Norte. No Brasil, atualmente, mais de $65 \%$ da produção de energia elétrica é proveniente da geração hidráulica (Epe, 2017). Essa é uma característica marcante do setor elétrico brasileiro que reflete a forte dependência dos recursos hídricos na geração de energia elétrica. De modo que, variações no padrão de chuvas ao longo dos anos tem impacto direto nas vazões afluentes aos reservatórios das UHEs e, certamente, com consequências importantes para o sistema de geração de energia. Embora interligados, os subsistemas geradores de energia têm diferentes regimes de chuva.

Nesse sentido, a previsão e o monitoramento de eventos meteorológicos extremos são de grande relevância para os projetos de geração de energia elétrica, atividades agrícolas e abastecimento de água, dentre outros (Santos et al. 2011). A partir do monitoramento de períodos úmidos e secos é possível obter informações no espaço e no tempo de características como duração, intensidade e severidade de sistemas atmosféricos atuantes, permitindo que as medidas preventivas sejam tomadas em curto prazo para diminuir impactos causados por fenômenos severos como enchentes e secas, e com isso causar diversos problemas na geração de energia elétrica no país.

No planejamento e programação da operação da geração e da transmissão de energia elétrica, pelo ONS, são adotados métodos de otimização a partir da programação dinâmica dual estocástica, as quais tratam as afluências aos aproveitamentos hidrelétricos através de cenários hidrológicos determinísticos para o $1^{\circ}$ mês do horizonte de estudo e probabilístico para os meses subsequentes até o final do horizonte de 5 anos.

Ao realizar as atividades, procura-se maximizar a utilização de geração hidrelétrica e assim reduzir os custos com a complementação térmica, a queima de combustíveis fósseis e a emissão de poluentes. É uma tarefa extremamente complexa, pois envolve uma grande quantidade de usinas, trata com a aleatoriedade das vazões afluentes, devido a variabilidade climática de cada região, vazões a jusante, as demandas futuras, restrições quanto ao armazenamento nos reservatórios, limites de intercâmbio na transmissão, entre outros.
A Bacia Hidrográfica do Rio São Francisco (BHSF) tem grande importância para o país, não só pelo volume de água transportado em uma região semiárida, mas também pelo potencial hídrico passível de aproveitamento energético e abastecimento hídrico na região Nordeste. De acordo com Silva e Brito (2008), o volume de água transportada pelo rio São Francisco tem uma grande importância, em relação a história, economia e ao desenvolvimento das populações ribeirinhas. Ao longo do seu curso, o volume transportado tem um grande potencial hídrico utilizado por projetos de irrigação e na geração de energia elétrica.

Nas últimas décadas, pesquisas desenvolvidas para avaliar o impacto da variabilidade climática nos recursos hídricos superficiais do país, tem comprovado que o efeito desse impacto pode trazer consequências sociais e econômicas graves tais como a destruição de lavouras, desemprego e fome. Esses efeitos são particularmente mais severos na região semiárida do Nordeste brasileiro cuja distribuição das chuvas é bastante irregular tanto na escala espacial quanto temporal (Barbieri, et al, 2017; Diniz, 2007; Marengo, 2003). Com o objetivo de analisar o impacto das mudanças climáticas no Nordeste a partir de estimativas das implicações sobre a disponibilidade de terras aptas para a atividade agrícola em um conjunto de cultivos, Domingues et al. (2008) chegou à conclusão que há um elevado potencial de perdas econômicas no Nordeste, principalmente nos estados mais próximos, apontando para a necessidade de políticas de mitigação e de controle de emissões.

Nos últimos anos, a ocorrência de um período de estiagem severa na região Nordeste (2012 a 2016) causou impactos no fornecimento de energia elétrica. Os baixos níveis dos reservatórios acarretaram danos em setores importantes da sociedade. Foi necessário acionar as usinas termelétricas o que elevou o preço da energia em função do uso de combustíveis em seu funcionamento (Ons, 2016). O efeito se concretizou na aplicação da bandeira tarifária vermelha na conta de luz dos consumidores. Apesar de 2011 ter sido um ano de chuvas regulares, com acúmulo de águas nos principais reservatórios da região Nordeste, o abastecimento d'água foi crítico a partir de 2012, se intensificou em 2015 (Marengo et al. 2016), e foi considerada uma das secas mais graves das últimas décadas, causando danos em muitos distritos das regiões semiáridas.

Em situações críticas decorrentes de níveis baixos dos reservatórios das hidrelétricas, o controle do setor elétrico brasileiro é feito com base em planejamento hidro- 
térmico que dependem das vazões afluentes futuras às Usinas Hidrelétricas (UHEs). As incertezas hidrológicas são consideradas por meio de cenários sintéticos de sequências de energias naturais afluentes (ENAs) às subregiões para os próximos cinco anos. Dois modelos computacionais são usados para otimizar o sistema: o NEWAVE (médio e longo prazo) e o DECOMP (curto prazo). Neste contexto, este trabalho tem como objetivo avaliar o desempenho do modelo NEWAVE, que utiliza a técnica da Programação Dinâmica Dual Estocástica (PDDE), na projeção das energias naturais afluentes (ENAs) e da energia armazenada (EAR) para o subsistema Nordeste em período de seca extrema.

\section{Materiais e Métodos}

\section{1. Área de estudo}

O Subsistema Nordeste é composto pela bacia hidrográfica do rio São Francisco (BHSF). O aproveitamento hidrelétrico do rio São Francisco representa a base do suprimento de energia da região, atualmente constituído por nove reservatórios importantes: Retiro Baixo, Três Marias, Queimado, Sobradinho, Itaparica, Moxotó, Paulo Afonso 1/3, Paulo Afonso 4 e Xingó (Fig. 1).

O reservatório da UHE de Sobradinho construído ao longo do rio São Francisco é o maior lado artificial da América Latina e está localizado no Médio São Francisco, cerca de $40 \mathrm{~km}$ a montante do polo agroindustrial Petrolina/PE - Juazeiro/BA e tem papel fundamental no armazenamento de água para geração de energia e na regula-

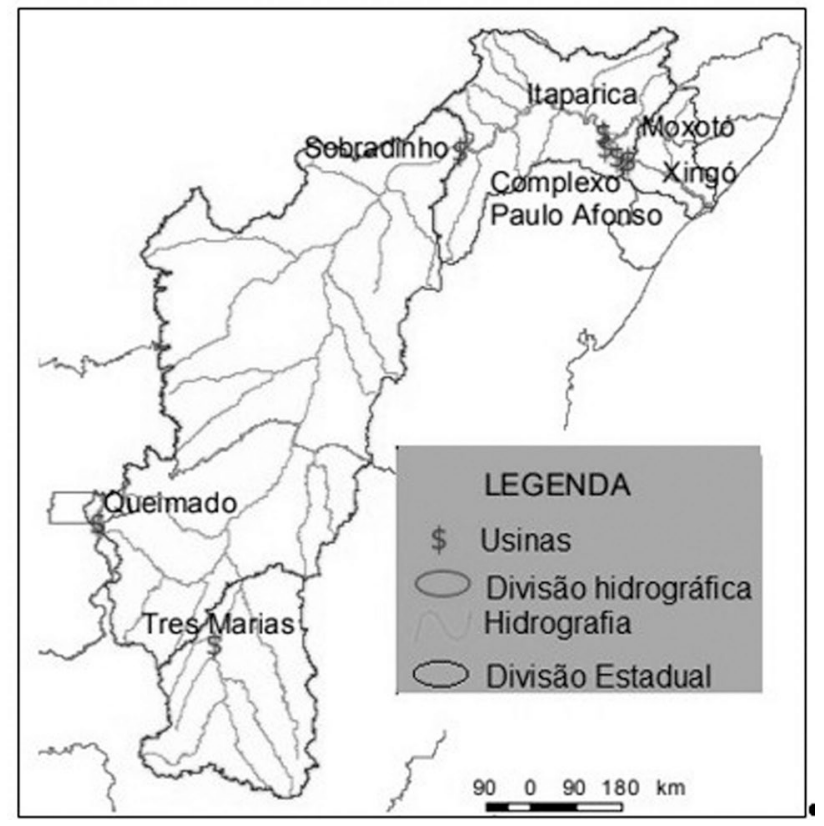

Figura 1 - Principais reservatórios da bacia hidrográfica do rio São Francisco. Fonte: Modificado de Ana 2004. rização dos recursos hídricos da região (Correia et al. 2006; Correia e Silva Dias, 2003).

Em função da grande extensão e localização geográfica da BHSF, reservatórios de uso múltiplos estão vulneráveis às variações climáticas e ambientais. Diferentes regimes de chuvas têm influência nas vazões afluentes e nas condições operacionais dos reservatórios. A ZCAS (Zona de Convergência do Atlântico Sul) é considerada por vários pesquisadores como o principal mecanismo produtor de chuvas na BHSF (Carvalho et al. 2002; Kodama, 1982; Lazaro, 2015), e os resultados mostram forte associação entre a ZCAS e mudanças no regime de vazões. Os impactos da ZCAS na BHSF são em toda sua extensão, pois o padrão de chuva associado consegue impactar positivamente os outros reservatórios da bacia.

\subsection{Material}

O Operador Nacional do Sistema (ONS) utiliza atualmente dois modelos computacionais para determinar a operação ideal do sistema. Nos procedimentos de curto prazo, é utilizado o DECOMP (Cepel, 2013a) e em médio/ longo prazo é utilizado o modelo NEWAVE (Cepel, 2013). Metodologias de otimização dos modelos são executados com a participação de integrantes diversos, principalmente representantes das empresas de geração e comercialização da energia em reuniões mensais denominadas como Programa Mensal de Operação (PMO).

Neste trabalho, o deck (conjunto de arquivos que engloba todos os parâmetros que são utilizados na determinação da Função de Custo Futuro (FCF), como por exemplo dados técnicos de usinas hidráulicas e térmicas, informações sobre intercâmbio de energia, restrições hidráulicas e elétricas) do NEWAVE de janeiro de 2012 disponibilizado pelo ONS foi utilizado na avaliação da projeção do período 2012 a 2016 feita para o subsistema Nordeste. Em seguida foram utilizados os arquivos de saída do modelo (Energia Natural Afluente (ENA) e Energia Armazenada (EAR)) para comparação entre o que foi previsto e o que foi observado no mesmo período (realizado).

Uma das principais saídas desse modelo são as FCF's (Fig. 2), que traduzem para os modelos de outras etapas (curto prazo) o impacto da utilização da água armazenada nos reservatórios.

Possíveis associações entre o comportamento das séries sintéticas de energias afluentes nos anos de 2012 a 2016 e registros de sistemas meteorológicos atuantes no mesmo período foram avaliadas com a finalidade de verificar o grau de influência desses sistemas na variabilidade das ENAs.

Mapas da distribuição espacial das chuvas e dos desvios em relação as médias climatológicas registradas no período de estudo foram obtidas no site do CPTEC/INPE e utilizadas como informações complementares na identificação de fatores ambientais importantes para compreensão 


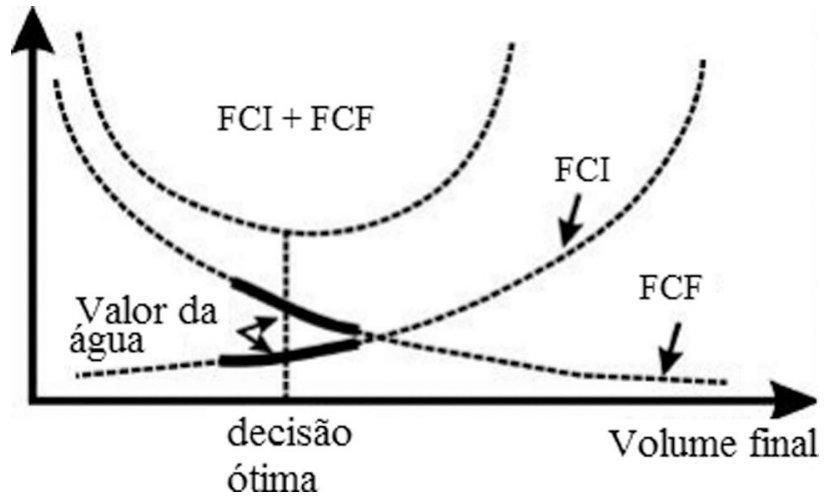

Figura 2 - FCF do Newave. Fonte: Simões e Gomes (2011).

dos resultados das ENAs obtidos com o modelo NEWAVE e/ou das vazões naturais afluentes.

\subsection{Métodos}

\subsubsection{O modelo newave}

O Newave emprega a técnica da Programação Dinâmica Dual Estocástica (PDDE) para definir mensalmente o quanto será gerado pelas usinas hidrelétricas e térmicas e os intercâmbios entre os subsistemas, atendendo à demanda de energia no país num horizonte de até 5 (cinco) anos. De acordo com Ramos (2011), esse procedimento visa a redução do custo total esperado do Custo Marginal de Operação (CMO). É utilizado para planejar o sistema hidrotérmico interligado brasileiro, transformando-o num sistema equivalente composto por quatro subsistemas de produção de energia e a malha principal de transmissão de energia entre estes subsistemas (Manual de referência Newave). O modelo é composto por 4 (quatro) módulos:

- Cálculo do Sistema Equivalente de Energia: representa as usinas nos quatro subsistemas equivalentes (Cepel, 2001);

- Geração de Séries Sintéticas: gera as séries sintéticas de ENAS do subsistema baseado na série histórica de vazões. É determinado também para cada subsistema a

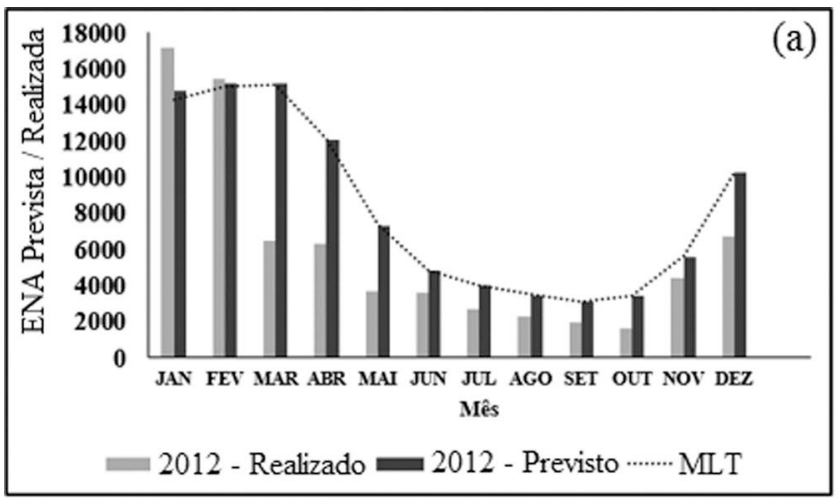

energia total afluente, que é composta pela energia controlável e pela energia a fio d'água (Cepel, 2001);

- Cálculo da Política de Operação Hidrotérmica: determina a política de operação ótima do sistema equivalente através da metodologia PDDE, considerando afluências futuras (Cepel, 2001);

- Simulação da Operação: determina a operação do sistema no horizonte de planejamento, considerando funções de custo futuro encontradas no módulo anterior. Risco de déficit, intercâmbios energéticos e montantes de geração hidrelétrica e térmica são algumas saídas deste módulo (Marcato, 2007).

Um outro aspecto importante é que os reservatórios equivalentes do Newave operam com energia e não explicitamente com reservatórios de água, portanto, a hidrologia é considerada pela Energia Natural Afluente (ENA) e Energia Armazenada (EAR) aos reservatórios.

A ENA a um subsistema é a soma das energias naturais afluentes a todas as usinas deste subsistema. Consiste no produto da vazão natural afluente a esta usina pela sua produtividade média. Apenas uma parcela da ENA produz energia, pois em períodos com excedentes hídricos acima da capacidade das turbinas, haverá vertimento.

A EAR de um subsistema é a soma dos produtos do volume armazenado em cada reservatório de acumulação pela produtividade média acumulada deste e de todas as usinas a jusante. A EAR máxima (ou Capacidade de EAR) corresponde à capacidade de cada subsistema considerando todo o volume útil de cada reservatório de acumulação.

\section{Resultados e Discussão}

A média de longo termo (MLT) e as energias afluentes (ENA) e armazenadas (EAR) previstas com o deck do NEWAVE de 2012 e realizadas (observadas) para o ano de 2012 são apresentadas na Fig. 3.

Observa-se que com exceção dos meses de janeiro e fevereiro, em que o modelo subestimou as energias afluentes observadas, as ENAs previstas para o período de

Figura 3 - a) Média de Longo Termo (MLT) e Energias Afluentes (ENAs) previstas e realizadas para o ano de 2012; b) Energia Armazenada (EARs) previstas e realizadas para o ano de 2012. 
março a dezembro ficaram bem acima do que foi observado no ano de 2012.

A seca que atingiu o Nordeste no início do ano foi considerada como a mais forte dos últimos 30 anos. A região mais afetada foi o semiárido nordestino, principalmente no estado da Bahia. A grande seca de 20122016, foi considerada a maior seca, tanto em magnitude quanto em duração, das últimas três décadas (Getirana, 2016; Brito et al. 2017; Marengo, et al. 2017a, 2017b).

O comportamento distinto observado nos valores previstos para os dois primeiros meses do ano (subestimativa) em relação aos demais (março a dezembro) pode ser explicado em função da atuação da ZCAS, um importante sistema meteorológico produtor de chuva na BHSF e com influência marcante na UHE de Três Marias situada no Alto São Francisco. As vazões excederam os correspondentes valores da MLT. A atuação desse sistema propiciou a elevação da ENA no Nordeste. Uma intensa atuação do fenômeno ZCAS faz com que o subsistema Nordeste eleve sua ENA e comercialize energia a um preço menor, caso essa atuação seja de fraca intensidade, influencia todo o SIN, fazendo com que a comercialização de energia ocorra em patamares maiores.

$\mathrm{Na}$ evolução temporal da energia armazenada EAR apresentada na Fig. 3, verifica-se que o modelo conseguiu reproduzir resultados aceitáveis, indicando uma diferença menor entre os valores previstos e observados. Neste caso, a explicação pode estar associada as chuvas ocorridas no período chuvoso do ano de 2011. O modelo é mais sensível a essa condição, predizendo melhor os parâmetros considerados, assim contribuindo de forma positiva para manter os níveis dos reservatórios elevados. É importante ressaltar que a gestão dos recursos hídricos, depende de vários fatores além da chuva, porém, em grandes períodos de estiagem, o maior desafio é definir estratégias para o uso da água uma vez que além do consumo natural de energia, a água acumulada nos reservatórios evapora ou é absorvida pelo solo em direção ao lençol freático.

Desvios de precipitação para os meses de janeiro e fevereiro de 2012 são apresentados na Fig. 4. Verifica-se que as chuvas ficaram abaixo da média climatológica. No entanto, a ENA atingiu cerca de 18.000 GWmédio. Esse resultado aparentemente contraditório, é consequência da atuação da ZCAS (desvio positivo em Minas Gerais) e consequentemente do aumento das vazões a jusante da UHE de Três Marias.

Segundo dados do NOAA, as condições climáticas indicavam ocorrências de índices pluviométricos abaixo da média no decorrer do ano, e esse cenário se configurou devido a manutenção dos padrões atmosféricos que já vinham ocorrendo desde o início do ano de 2012. No mês de dezembro, ocorreu alguns indícios de mudanças climáticas, considerando que nessa época o Atlântico na costa do Pará, Maranhão, Piauí e Ceará era para estar mais quente. Um fato importante a ser notado é que neste mês, as águas do Atlântico na costa desses estados oscilaram entre resfriamento e aquecimento, oscilando entre $0,5{ }^{\circ} \mathrm{C}$ e $1{ }^{\circ} \mathrm{C}$ acima da média. Essa condição tende a impactar negativamente as condições de regularidades para chuvas na região.

O período de 2012 a 2016 foi associado a migração para o norte da ZCIT e em seguida por um evento El Niño. Gloor et al. (2013) sugeriram que os SST tropicais mais quentes do que a média do Atlântico Norte bloqueiam na ZCIT mais ao norte do que o habitual, com a mudança levando a menos precipitação geral em toda a bacia. Em outro estudo, Gloor et al. (2015) sugeriram que as tendências observadas no Atlântico tropical aumentaram a frequência de inundações extremas e condições mais secas do que o habitual na bacia amazônica.

As energias afluentes (ENAs) previstas e realizadas nos anos de 2013, 2014, 2015 e 2016, são apresentadas na Fig. 5. Em geral, a previsão é de afluências próximas da

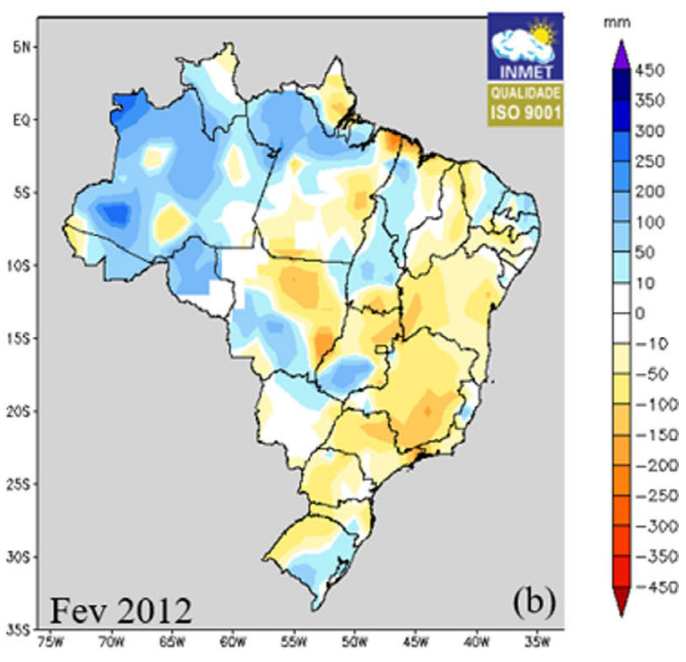

Figura 4 - Desvio da precipitação: (a) janeiro de 2012 e (b) fevereiro de 2012. Fonte: INMET (2012). 

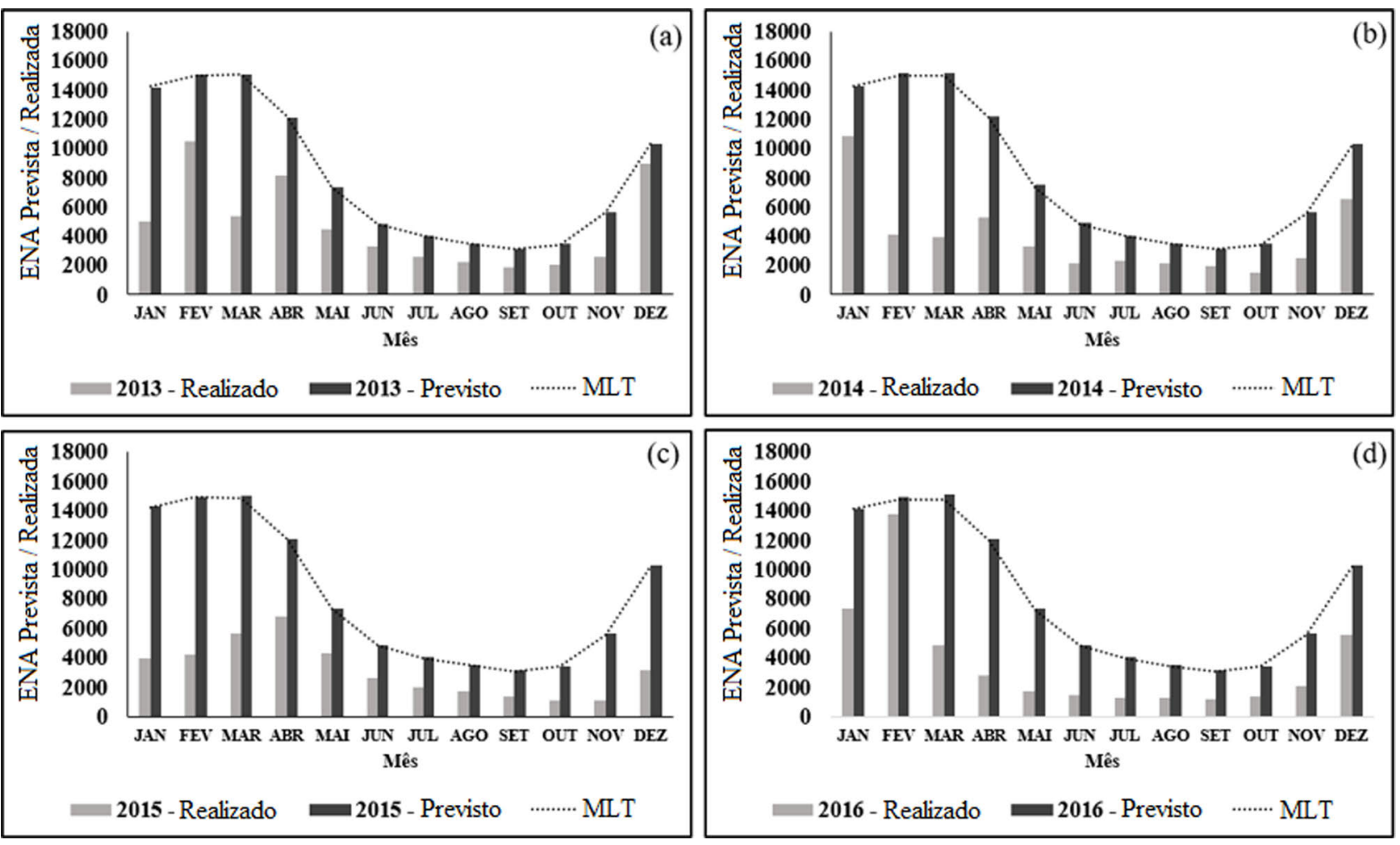

Figura 5 - a) ENAs previstas e realizadas para: (a) 2013; (b) 2014; (c) 2015; (d) 2016.

MLT (Média de Longo Tempo). Diferenças resultantes dos valores extremamente altos das ENAs previstos pelo modelo quando comparados com os observados independente do período (úmido/seco) indicam uma forte tendência do modelo de superestimar as energias afluentes, porque além do modelo utilizar a série histórica para projetar os cenários à frente, também usa como referência o ano anterior. Deste modo, foi utilizado o ano de 2011, ano chuvoso, com o maior peso para projetar os cenários futuros superestimados.

É possível que em decorrência da estiagem prolongada na região, as limitações típicas dos modelos autoregressivos se tornem mais evidentes. A contribuição das afluências provenientes da UHE de Três Marias não foi suficiente para manter o nível do reservatório de Sobradinho. A região vivenciou um período crítico de escassez, gerando problemas em diversas áreas, da sociedade.

A influência da sazonalidade é visível em todos os casos analisados (2013, 2014, 2015 e 2016) mostra nitidamente uma queda nos valores observados, em decorrência do período de estiagem. O efeito também é perceptível na visão conjunta em decorrência da seca prolongada que atingiu a região Nordeste. Na região de Sobradinho, onde localiza-se o reservatório que compõe o Subsistema Nordeste a situação foi classificada como alarmante.

Segundo Marengo et al. (2017), a seca que afetou o Nordeste de 2012 a 2015 teve intensidade e impacto que não foram vistos em várias décadas, destruindo grandes áreas de cultivo, chegando a afetar centenas de cidades e vilarejos da região, deixando os fazendeiros lutando pela alimentação e água. As projeções futuras do clima mostravam grandes aumentos de temperatura e reduções de chuvas e todas essas condições levavam a um aumento na evaporação de reservatórios e lagos, afetando a irrigação e a agricultura, bem como os principais usos da água, incluindo energia hidrelétrica e indústria, e, portanto, o bem-estar dos moradores.

No período úmido de 2015 (janeiro a abril) são observadas as maiores diferenças entre os valores previstos e observados. Esse resultado indica que episódios de estiagens severas podem diminuir a eficácia do modelo ou contribuir para superestimar os valores das ENAs. Gonçalves (2015) também observou que há incerteza do modelo ao analisar as séries sintéticas para os anos 2013 e 2014 no subsistema Nordeste e chegou à conclusão que o mesmo tende a superestimar os valores de ENA, provocando um grande descolamento da realidade.

No período 2015 e 2016, a região esteve sob a influência do fenômeno El Nino. Os principais efeitos no Brasil são o aumento anormal das temperaturas e chuvas no Sul, Sudeste e secas severas no Nordeste. De acordo com a NASA (Agência Espacial Americana), o fenômeno El Nino 2015-2016 pôde ser comparado aos episódios de forte intensidade que ocorreram em 1982-1983 e 19971998, tidos até então como os de maior impacto no século passado. Isso se confirmou com efeitos marcantes em 
dezembro de 2015. O reservatório de Sobradinho atingiu níveis bastante baixos, prestes a atingir volume morto.

Nota-se que as ENAs de 2015 e 2016 ficaram bem abaixo da MLT principalmente em 2015. Em 2016 apresentou uma breve recuperação, mas logo em seguida os níveis voltaram a diminuir. O fenômeno ENOS (El NinoOscilação Sul) tem impactos diretos na quantidade e distribuição de chuvas no Brasil e em muitas ocasiões com reflexos acentuados nos recursos hídricos (Mendonça; Oliveira, 2011; Iapar, 2015; Inpe/Cptec, 2016).

As energias armazenadas (EAR) previstas e observadas para os anos de 2013, 2014, 2015 e 2016, são apresentados na Fig. 6. Os resultados obtidos permitiram avaliar o grau de aproximação entre os valores estimados e verificados.

A tendência de superestimação pelo modelo é evidente. No entanto, a diferença entre os valores previstos e observados é consideravelmente maior nos anos de 2015 e 2016. Como o esvaziamento progressivo dos reservatórios foi constatado ano após ano, tanto os resultados previstos quanto os observados indicam claramente a redução nos valores da EAR.

Notadamente em função do período crítico de estiagem prolongada não houve recuperação dos reservatórios em nenhum momento. Embora o modelo tenha sido hábil em indicar a tendência de queda nos valores estimados, as diferenças relativamente altas entre os valores previstos $\mathrm{e}$ os observados indicam a necessidade de ajustes na metodologia principalmente em situações de estiagens severas.

Os principais dados de entrada nos modelos utilizados pelo ONS em simulações de energias afluentes aos reservatórios são séries de vazões afluentes fortemente influenciadas por condições climáticas.

Através das projeções de ENA e EAR feitas pelo modelo Newave, observou-se quão frequente são os impactos da seca na geração de energia elétrica ao comparar com os dados realizados. Vazões e armazenamentos cada vez menores impactaram diretamente no preço da energia para esse período crítico de seca severa, uma vez que o subsistema Nordeste foi comercializado a um preço mais alto, diferente dos outros subsistemas.

Um aspecto relevante e que deve ser considerado nas avaliações de desempenho dos modelos usados no planejamento de operações em reservatórios do Nordeste é o fato dos mesmos terem sido projetados quando o rio São Francisco apresentava vazões muito acima dos valores atuais. O que pode ser observado na Fig. 7 a seguir é que após o ano de 2012, a vazão do rio São Francisco foi decaindo cada vez mais e o ano mais crítico desse período foi o de 2015.

Atualmente, a operação de Sobradinho é mais complexa, pois não se consegue estocar água por muito tempo, uma vez que um grande espelho d'água também equivale a maiores perdas de água pelo processo de evaporação.
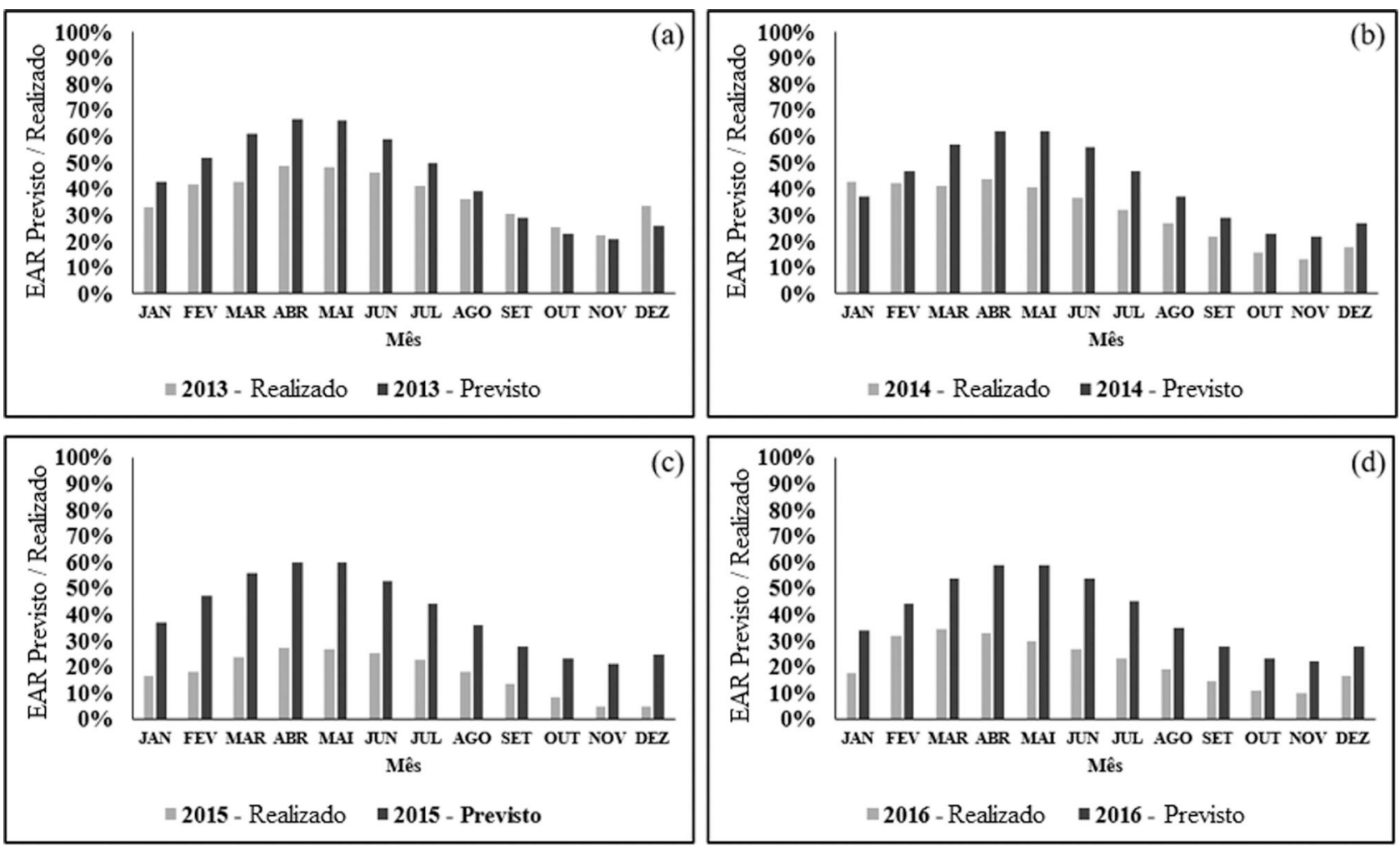

Figura 6 - a) EAR previstos e realizados para o ano de 2013; b) EAR previstos e realizados para o ano de 2014; c) EAR previstos e realizados para o ano de 2015; d) EAR previstos e realizados para o ano de 2016. 

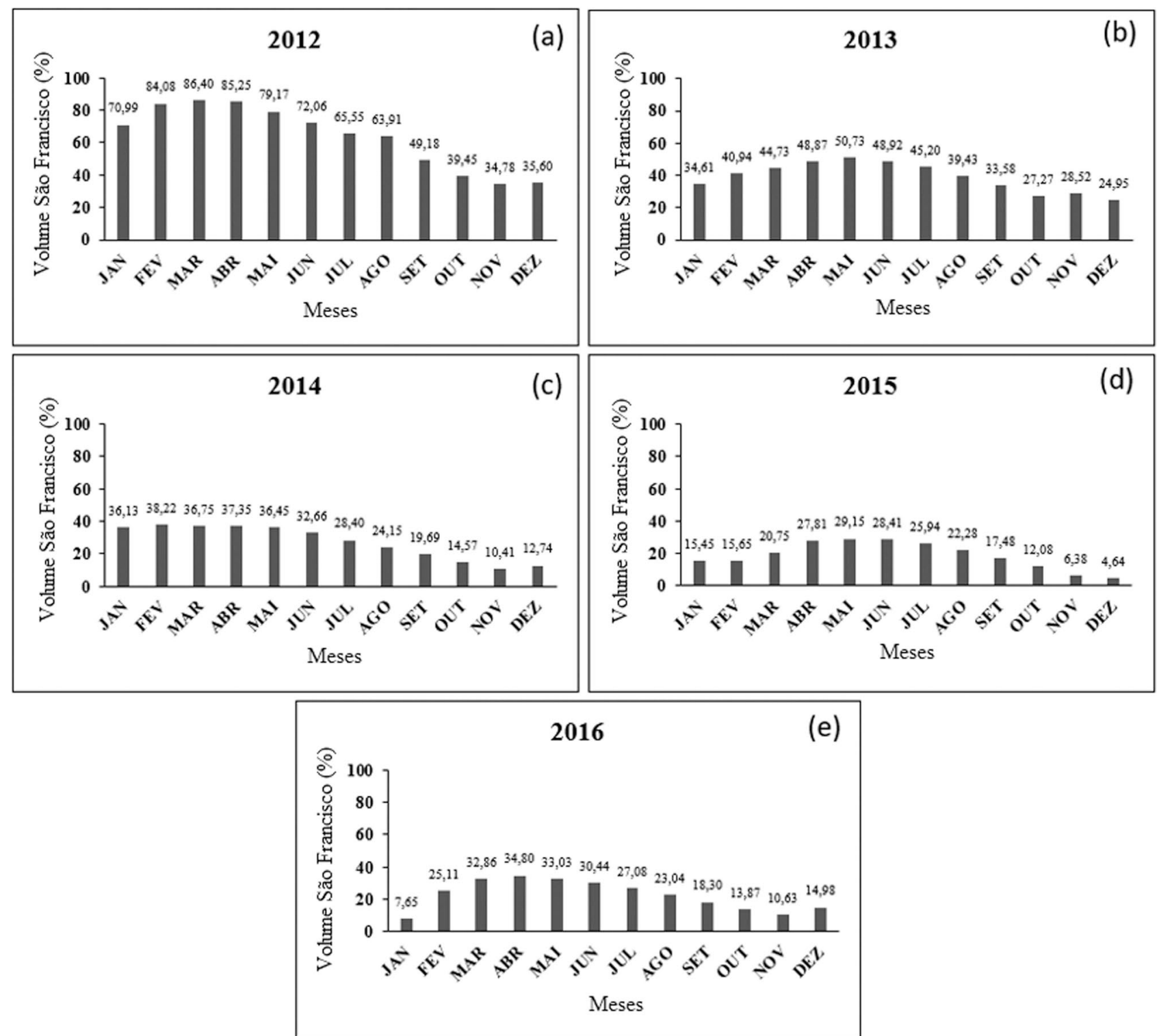

Figura 7 - Volume do rio São Francisco referente aos anos de (a) 2012; (b) 2013; (c) 2014; (d) 2015.

Em situações de crise essas perdas são consideradas como "desperdício", sobretudo na geração de energia e em outras práticas de uso do reservatório.

Desde o ano de 2014 o Nordeste vem dependendo energeticamente dos outros subsistemas durante a maior parte do ano, devido ao impacto na geração hidrelétrica causado pela irregularidade nas chuvas em Três Marias MG, Sobradinho - PE e Itaparica - BA. O maior impacto ocorre na região de Sobradinho, que vem de um período de estiagem muito prolongado e intenso causando vários problemas socioeconômicos além do próprio déficit de geração de energia elétrica. Como solução para este problema, fomentou-se a utilização de energia eólica nesse subsistema, sendo mais expressiva nos meses de julho, agosto e setembro devido à velocidade dos ventos ser maior nesse período. $\mathrm{O}$ resultado vem se mostrando bastante positivo, uma vez que em determinadas épocas do ano o Nordeste exporta energia para o subsistema mais expressivo do SIN, o Sudeste/Centro-Oeste (SE/CO).

Uma questão majoritária é a previsão das vazões para minimização do PLD (Preço da Liquidação das Diferenças), onde não se consegue antever o problema da seca e armazenar água o máximo possível despachando térmicas baratas em momentos de abundância de água. No decorrer desse período de seca o PLD do Nordeste chegou a um patamar que desde então não consegue mais voltar, ao menos que esta crise seja superada. Para o período úmido, onde o PLD normalmente é um valor comerciado mais barato, em 2011 esse valor médio era de aproximadamente $\mathrm{R} \$ 37,00$ e após esse período, a partir de 2012, 
a energia desse subsistema passou a ser comercializada pelo valor de aproximadamente $\mathrm{R} \$ 282,57$ no período úmido e no período seco atingiu valores mais altos.

O modelo utilizado pelo ONS na previsão de vazões, não é o mesmo utilizado no planejamento de novas usinas. Dados contidos no Plano Decenal de Energia (documento da EPE) dos anos 2011, 2012 e 2013 mostram que não houve mudança nos planejamentos dos novos projetos nem na garantia física das usinas (que é modificada sob pedido do agente gerador ou de $5 \mathrm{em} 5$ anos). Isso ocorre por não se considerar eventos pontuais para determinar a gestão de obras.

\section{Conclusões}

O modelo usado pelo ONS prioriza a geração hidrelétrica sobre a térmica como o método mais adequado na garantia de um nível de armazenamento mínimo nos reservatórios. No entanto, os resultados deste estudo, permitiram concluir que os valores das séries sintéticas gerados pelo modelo Newave foram substancialmente mais altos que os valores verificados nos anos de 2012, 2013, 2014 e 2015

As afluências ao reservatório de Sobradinho dependem fortemente do regime de chuvas do Alto São Francisco.

O modelo foi hábil em indicar a tendência de queda nos valores da EAR no período de estiagem. No entanto, ficou bem abaixo dos valores observados. O Newave não tende a utilizar informação da última estação com maior peso, e sim informação do último ano.

As diferenças relativamente altas entre os valores previstos e os observados indicam a necessidade de ajustes na metodologia principalmente em situações de estiagens severas. Em qualquer um dos períodos do ano, o peso maior para a entrada do modelo sempre será a ENA, pois a precipitação é o que faz a diferença na estimativa do modelo.

O desempenho do modelo na previsão da Energia Armazenada (EAR) é relativamente melhor do que para a previsão de Energia Natural Afluente (ENA), devido ao EAR ser algo controlável, já a ENA é uma variável que depende única e exclusivamente de precipitação nas bacias que compõem o SIN. Além disso, para a projeção de ENA, o histórico de precipitação (1931-2010) e o ano de 2011 são usados como condição inicial no modelo. Esse ano de 2011 terá um peso maior e caso seja chuvoso, a projeção das ENAs também será maior.

Uma das alternativas para minimizar esse efeito, será a entrada do modelo DESSEM, onde além de informações de ENA, EAR, terá também dados de Vento, Solar, que serão também entradas do modelo. Previsão de entrada do modelo: jan/21.

\section{Agradecimentos}

À Coordenação de Aperfeiçoamento de Pessoal de Nível Superior (CAPES) pelo auxílio financeiro através bolsa de estudos e à Comercializadora Kroma Energia Ltda pela cessão de dados e apoio para realização dessa pesquisa.

\section{Referências}

BARBIERI, L.F.P.; CORREIA, M.F.; SILVA ARAGÃO, M.R.S.; VILAR, R.A.A.; MOURA, M.S.B. Impact of climate variations and land use change: A Mann-Kendall Application. Revista Geama, v. 3, p. 127-135, 2017.

BRITO, S.S.B.; CUNHA; APMA; CUNNINGHAM, C.C.; ALVARÁ, R.C.; MARENGO, J.A.; CARVALHO, M.A. Frequência, duração e severidade da seca na região semiárida do Nordeste do Brasil. International Journal of Climatology, v. 38, p. 517-529, 2017.

CARVALHO, L.M.V.; JONES, C.; LIEBMANN, B. The South Atlantic convergence zone: Persistence, intensity, form, extreme precipitation and relationships with intraseasonal activity. J. Climate, v. 17, p. 88-108, 2002.

CEPEL - Centro de Pesquisa de Energia Elétrica. Projeto NEWAVE: Modelo Estratégico de Geração Hidrotérmica a Subsistemas Equivalentes. Manual do usuário. Versão 17.5.3. Brasil, 2013. Disponível em: http://www2. aneel.gov.br/aplicacoes/audiencia/arquivo/2013/086/docu mento/manualusuario.pdf, acesso em: 24 set. 2018.

CEPEL - Centro de Pesquisa de Energia Elétrica. Modelo DECOMP: Determinação da Coordenação da Operação a Curto Prazo. Manual do usuário. Versão 18.3. Brasil, 2013a. Disponível em: http://www2.aneel.gov.br/ aplicacoes/audiencia/arquivo/2013/086/documento/manua lusuariodecompv18.3.pdf, acesso em: 24 set. 2018.

CORREIA, M.F.; DIAS, M.A.F.; SILVA ARAGÃO, M.R.S. Soil Occupation and atmospheric variations over Sobradinho Lake area. Part two: A regional modeling study. Meteorology and Atmospheric Physics, v. 94, p. 115-128, 2006.

CORREIA, M.F.; SILVA DIAS, M.A.F. Variação do nível do reservatório de Sobradinho e seu impacto sobre o clima da região. Revista Brasileira de Recursos Hídricos, n. 1, v. 8, p. 157-168, 2003.

DOMINGUES, E.; MAGALHÃES, A.S.; RUIZ, R.M. Cenários de Mudanças Climáticas e Agricultura no Brasil: Impactos Econômicos na Região Nordeste. Universidade Federal de Minas Gerais, Belo Horizonte, Textos para Discussão n. 340, 25 pp, 2008.

EPE. EMPRESA DE PEQUISA ENERGÉTICA. Disponível em: http://www.epe.gov.br/sites-pt/publicacoes-dados-abertos/ publicacoes/Publicacoes Arquivos/publicacao-332/topico435/Consolida $\%$ C3\%A7\%C3\%A30\%20-\%20Tex to $\%$ 20CAP11.pdf, 2017, acesso em: 24 set. 2019.

GETIRANA, A. Déficit hídrico extremo no Brasil detectado no espaço. Journal of Hydrometeoroly, v. 17, 591 - 599, 2016.

GONÇALVES, S.R.S. Análise das séries sintéticas de energia natural afluente bruta da região nordeste do Brasil. Simpósio Brasileiro de Pesquisa Operacional - XLVII SBPO, p. 919-928. Porto de Galinhas, 2015. 
INSTITUTO AGRONÔMICO DO PARANÁ. Produtividade da Soja no Entorno do Reservatório de Itaipú. IAPAR, Londrina, p. 217, 2015.

INSTITUTO NACIONAL DE PESQUISAS ESPACIAIS/CENTRO DE PREVISÃO DE TEMPO E ESTUDOS CLIMÁTICOS. Impactos do fenômeno ENOS, 2016. Disponível em: http://enos.cptec.inpe.br/, acesso em: 23 ago. 2018.

INSTITUTO NACIONAL DE METEOROLOGIA. Boletim Agroclimatológico Mensal, v. 47, n. 12, 2013.

KODAMA, Y. Large-scale common features of subtropical precipitation zones (the Baiu Frontal Zone, the SPCZ, and the SACZ). Part II: Conditions for gerenating the STCZs. J. Meteor. Soc., v. 71, n. 4, p. 581-610, 1982.

LÁZARO, Y.M.C. Mudança Climática no Nordeste do Brasil, Amazônia e Bacia do Prata: Avaliação dos Modelos do IPCC e Cenários para o Século XXI. Dissertação de Mestrado em Engenharia Civil e Recursos Hídricos, Centro de Tecnologia, Universidade Federal do Ceará, 89 p. 2011.

MARCATO, R.M. Redistribuição ótima em patamares de carga da geração mensal de usinas hidrelétricas. Dissertação de Mestrado. IMPA. Rio de Janeiro, 2007.

MANUAL DE REFERÊNCIA NEWAVE. Disponível em: NWRefer_ncia.PDF, acesso em: 10 de ago. 2018.

MARENGO, J.A. Condições climáticas e recursos hídricos no Norte brasileiro. In: TUCCI, C.E.; BRAGA, B. (Eds). Clima e recursos hídricos no Brasil. Porto Alegre, RS: Associação Brasileira de Recursos Hídricos. FBMC/ANA, v. 9, p. 117-161, 2003.

MARENGO, J.A.; ALVES, L.M.; SOARES, W.R.; RODRIGUEZ, D.A.; CAMARGO, H.; RIVEROS, M.P.; PABLÓ, A.D. Two Contrasting Severe Seasonal Extremes in Tropical South America in 2012: Flood in Amazonia and Drought in Northeast Brazil. J Clim. v. 26, p. 9137-9154, 2016.

MARENGO, J.A.; TORRES, R.R.; ALVES, L.M. Seca no Nordeste do Brasil - passado, presente e futuro. Teoria e Climatologia Aplicada, v. 129, p. 1189-1200, 2017a.

MARENGO, J.A.; ALVES, L.M.; ALVALA, R.C.; CUNHA, A.P.; BRITO, S.S.; MORAES, O.L.L. Características climáticas da seca de 2010 a 2016 na região semiárida do nor- deste do Brasil. Anais da Academia Brasileira de Ciências, v. 90, n. 2, p. 1678-2690, 2017 b.

MENDONÇA, F.; OLIVEIRA, I.M.D. Climatologia: Noções Básicas e Climas do Brasil. Oficinas de Textos, São Paulo, 206 p, 2011.

ONS - OPERADOR NACIONAL DO SISTEMA ELÉTRICO, 2016. Disponível em https://agentes.ons.org.br/publicacao/ ophen/, acesso em 24 set. 2018.

RAMOS, T.P. Modelo Individualizado de Usinas Hidréletricas Baseado em Técnias de Programação não Linear Integrado com o Modelo de Decisão Estratégica. Dissertação de Mestrado. Universidade Federal de Juiz de Fora. Juiz de Fora, 2011.

SANTOS, E.P.; CORREIA, M.F.; ARAGÃO, M.R.S.; SILVA, F.D.S. Eventos extremos de chuva e alterações no regime hidrológico da Bacia Hidrográfica do Rio São Francisco: Uma aplicação do índice RAI (Rainfall Anomaly Index). Engenharia Ambiental, v. 8, p. 315-330, 2011.

SILVA, D.F.; BRITO, J.I.B., Variabilidade do vento na bacia hidrográfica do rio São Francisco durante a ocorrência da ZCAS. Ambiência (UNICENTRO), v. 2, p. 24-47, 2008.

SIMÕES, M.D.D.P.; GOMES, L.L. Decisão de sazonalização de contratos de fornecimento de energia elétrica no Brasil através da otimização da medida Ômega $(\Omega)$. Revista Eletrônica de Administração, Porto Alegre, n. 1, v. 17, 2011.

\section{Seção Internet Resources / Endereços de Internet}

http://www2.aneel.gov.br/aplicacoes/audiencia/arquivo/2013/ 086/documento/manualusuario

http://www2.aneel.gov.br/aplicacoes/audiencia/arquivo/2013/ 086/documento/manualusuariodecompv18.3.pdf

http://www.epe.gov.br/sites-pt/publicacoes-dados-abertos/publi cacoes/PublicacoesArquivos/publicacao-332/topico-435/ Consolida $\%$ C3\%A7\%C3\%A3o\%20-\%20Texto\% 20CAP11.pdf

http://enos.cptec.inpe.br/

https://agentes.ons.org.br/publicacao/ophen/

License information: This is an open-access article distributed under the terms of the Creative Commons Attribution License (type CC-BY), which permits unrestricted use, distribution and reproduction in any medium, provided the original article is properly cited. 